\title{
Critical appraisal of extended-release hydrocodone for chronic pain: patient considerations
}

\author{
This article was published in the following Dove Press journal: \\ Therapeutics and Clinical Risk Management \\ 22 October 2015 \\ Number of times this article has been viewed
}

\author{
Harry J Gould III 1,3-7 \\ Dennis Paul ${ }^{1-8}$ \\ 'Department of Neurology, \\ ${ }^{2}$ Department of Pharmacology \\ and Experimental Therapeutics, \\ ${ }^{3}$ Department of Internal Medicine, \\ Section of Physical Medicine and \\ Rehabilitation, ${ }^{4}$ Department of \\ Anesthesiology, ${ }^{5}$ Neuroscience \\ Center of Excellence, ${ }^{6}$ Center of \\ Excellence for Oral and Craniofacial \\ Biology, ${ }^{7}$ Pain Mastery Center of \\ Louisiana, ${ }^{8} \mathrm{Alcohol}$ and Drug Abuse \\ Center of Excellence, Louisiana State \\ University Health Sciences Center, \\ New Orleans, LA, USA
}

\begin{abstract}
Opioid analgesics are currently the most effective pharmacologic option for the management of both acute and chronic forms of moderate-to-severe pain. Although the "asneeded" use of immediate-release formulations is considered optimum for treating acute, painful episodes of limited duration, the scheduled dosing of extended-release formulations with immediate-release supplementation for breakthrough pain is regarded to be most effective for managing chronic conditions requiring around-the-clock treatment. The recent introduction of extended-release formulations of the opioid analgesic hydrocodone potentially broadened the possibility of providing pain relief for individuals for whom current formulations are either ineffective or not tolerated. However, reaction to the approval of the new formulations has fueled controversy over the general safety and need for opioid medications, in light of their potential for misuse, abuse, diversion, and addiction. Here, we discuss how the approval of extendedrelease formulations of hydrocodone and the emotionally charged controversy over their release may affect physician prescribing and the care available to patients in need of chronic opioid therapy for the management of pain.

Keywords: opioid analgesics, patient risks, patient benefits, misuse, addiction
\end{abstract}

\section{Introduction}

With the introduction and approval of "something new" comes anticipation and hope for improvement in the status quo and the promise of better things to come. However, amid guarded optimism surrounding the announcement of the release of new extendedrelease formulations of the opioid analgesic, hydrocodone (Zohydro ER ${ }^{\circledR}[$ Pernex Ireland Pain Limited, Pernex Therapeutics, LLC, Morristown, NJ, USA] and Hysingla ER $^{\circledR}$ [Purdue Pharma L.P., Stamford, CT, USA]), questions have been raised as to the prudence of introducing yet another opioid medication into the clinical arena at a time when there has been growing awareness and concern about the inordinate number of overdose-related deaths and hospital admissions attributable to the overprescribing of opioid analgesic medications. ${ }^{1-6}$ The controversy has promoted intense discussion and awakened skepticism as to whether the use of opioids is justified and whether they should have any role in the treatment of chronic pain of nonmalignant origin. ${ }^{7,8}$ The heightened awareness about the real and imagined negative aspects associated with prescribing opioid medications in general and prescribing the new extended-release formulations of hydrocodone for the management of pain severe enough to require daily, around-the-clock, long-term opioid treatment in particular, has reinforced deepseeded fears and ultimately may negate most of the benefits anticipated when the new extended-release formulations of hydrocodone were introduced.

Pain is one of the most frequent reasons that people seek the counsel of a health care professional. ${ }^{9-11}$ In its acute form, pain is essential for survival and for reducing 
the severity of injury. In its chronic form, however, pain negatively affects a patient's mood, health, and quality of life and is a major drain on the economy both in lost productivity in the work force and on health care spending amounting to billions of dollars annually. ${ }^{3,9,10}$ Over onethird of Americans live with chronic or recurrent pain; ${ }^{4} \mathrm{a}$ significant percentage of these individuals fail treatment due to intolerable adverse effects, to a lack of efficacy due to single nucleotide polymorphism variants ${ }^{12-14}$ or to the development of tolerance ${ }^{15}$ with the available formulations. Unfortunately, a clear, safe, and effective pharmacologic panacea for managing chronic pain is neither available nor on the distant clinical horizon, leaving opioid medications, in spite of the inherent risks, as the mainstay for the pharmacologic management of both acute and chronic forms of moderate-to-severe pain. Opioid medications have long been accepted for their use in the treatment of acute pain and for pain associated with terminal disease. ${ }^{16,17}$ However, in the treatment of chronic pain, there is a constant struggle to find a balance between the relief of suffering and improving patient quality of life and the elimination of the untoward problems associated with limited long-term benefits and the high incidence of significant adverse effects. $^{4,8}$ In an environment where a significant portion of society uses opioid analgesics for recreational, nontherapeutic purposes, ${ }^{18,19}$ the abuse, diversion, and inadvertent misuse of prescription analgesic medications is a significant and ever-increasing problem that is harmful to the users and their psychosocial networks. This aberrant behavior results in personal injury, loss of functionality, death, and increased costs for law enforcement and regulating agencies dealing with addiction, drug trafficking, and violent crime. ${ }^{2-6}$ It is in this context that extended-release hydrocodone formulations have been introduced.

\section{The need for "single-drug" formulations}

Although hydrocodone was originally marketed as a "singledrug" formulation, combinations of hydrocodone with an analgesic adjuvant soon captured the market. The combinations of hydrocodone with acetaminophen, ibuprofen, and aspirin are all available, with the acetaminophen combinations being most widely prescribed. The hydrocodone-acetaminophen combination is considered to have two advantages over hydrocodone alone. First, because the analgesic mechanisms and adverse effect profiles for hydrocodone and acetaminophen are different, additive or synergistic analgesia can be achieved without a concomitant increase in adverse effects. Second, the hepatotoxicity of acetaminophen was thought to limit the dosing of the combination as tolerance develops. Until 2011, formulations containing as much as $750 \mathrm{mg}$ of acetaminophen, the maximum recommended dose, were available, but due to a high incidence of hepatotoxicity for those who develop tolerance to the opioid effect and for those who abuse these combination drugs and the frequency of potentially fatal skin rashes, the US Food and Drug Administration requested the limiting of single doses to no more than $325 \mathrm{mg}$ by $2014 .^{20,21}$ With these changes, practitioners have become more aware of the risks associated with dose escalation of acetaminophen-hydrocodone combinations.

\section{Anticipated improvements for patients and prescribers}

Acute pain is generally well-recognized and well-managed by most physicians and health care providers. By contrast, chronic pain is less well understood. The chronic form of pain is frequently viewed as a phenomenon that is identical to the acute form only of longer duration. That chronic pain is multifaceted and fundamentally different from acute pain imposes challenges both for those who must live with such conditions and for those responsible for managing its treatment. In chronic conditions, the inciting cause may be untreatable or may be progressive and thus require long-term care. In such cases, it is important to reduce discomfort to a level that enables an individual to perform activities essential for slowing the progression of the disease and maintaining independence, quality of life, and overall health in spite of a chronic condition. This treatment goal is often best achieved by regularly scheduled (around-the-clock) dosing of an analgesic medication with occasional additional doses provided as needed for incidental, breakthrough pain. ${ }^{22-25}$ The routine dose should be sufficiently large enough to adequately reduce discomfort without causing peak dosing adverse effects and frequent enough to prevent regular or frequent end dose escalation of discomfort that often disrupts sleep and requires supplemental breakthrough dosing. ${ }^{26-28}$ Regular dosing is also favored in an attempt to preempt the escalation of discomfort to levels that would otherwise require higher or supplemental analgesic doses to provide relief. As with patient-controlled analgesia, which has been shown to be optimally effective for treating postoperative pain in the in-patient setting when properly monitored, ${ }^{29-32}$ routine dosing generally reduces the effects of pain-contingent operant conditioning and achieves better analgesic coverage with less medication. Routine dosing 
thus potentially reduces the negative effects associate with long-term treatment with as needed dosing. ${ }^{23}$ Regrettably, the use of frequent doses of immediate-release formulations that are typically effective for only 4-6 hours for this purpose disrupts sleep and the performance of daily activities and imposes often unmanageable complications for optimum compliance. ${ }^{27}$ In addition, the nervous system functions to assess and respond to change rather than steady states. Thus, immediate-release formulations impart up to four to six perceivable changes in pain within a 24-hour period in relation to the regular and rapid oscillation of peak and trough analgesic levels that are independent of the state of the pain generator. The fluctuations in analgesic level trigger conditioned passive pill-taking behavior associated with the perceived necessity to take medication to reestablish comfort rather than encouraging the patient to take an active role in care. ${ }^{26,27}$ Because extended-release formulations generally require less frequent, easier to remember dosing, they tend to diminish the rapid perceivable change sought by many addicts, decrease the development of tolerance, and improve coverage and compliance while reducing the need for acute analgesic supplementation. ${ }^{17,27,28,33,34}$ Improved regularity of dosing and less frequent drug-induced variations in analgesic coverage further improves the potential for assessing changes in the underlying condition responsible for the pain for both the patient and the treating physician because the changes in pain level would be more likely due to changes in the underlying pathology than to changes in the level of the analgesic provided.

The anticipated improvement in the status quo associated with the introduction of the extended-release formulations of hydrocodone is that those patients for whom hydrocodone is currently the only effective treatment will be able to realize the benefits of more uniform pain relief and less disruption of the normal daily activities necessary for quality of life. In addition, it is anticipated that these patients will enjoy an improved margin of safety due to the lack of compulsory add-on medications ${ }^{1}$ and will have available an additional resource for use in drug rotation strategies when needed. ${ }^{35}$ With improved pain control in receptive patients, physicians should experience an improved ability to monitor treatment efficacy and adverse reactions and may find it easier to manage underlying and comorbid conditions responsible for the pain.

Despite the potential for significant improvements in care, both patients and physicians must be acutely aware that the anticipated benefits associated with the new extendedrelease medications do not come without significant risk and an added burden of responsibility related to the importance of compliance to treatment, to understand the basic differences between formulations for medication delivery and elimination, and the differences in anticipated response. ${ }^{1,16,36}$ First, patients must be aware that the medication delivery systems are designed to control the release of medication and that the relatively rapid onset of relief that they may be used to when taking immediate-release medications should not be anticipated. Instead, the analgesic benefit will become evident over an extended period of time. It should be understood that the slow onset of relief does not mean that the medication is not working and that taking a second tablet in an attempt to hasten the onset of pain relief may lead to a delayed toxic effect or overdose. Second, because of the slow, controlled release, the extended-release formulations will usually contain larger amounts of drug in a single pill, often an amount equal to that contained in two or three of the immediate-release tablets they have been familiar with taking. ${ }^{1,16,36}$ It is therefore imperative that these medications be stored where they will not be used by anyone other than the person for whom they are intended. Third, sharing high-dose medications with sustained release properties should never be done, because sharing of highdose formulations carries an even higher risk of adverse effects, including death, than when lower dose, immediaterelease formulations are taken by someone that responds adversely to the drug. The increased risk is not only due to the greater amount of drug consumed, but the length of time that the adverse effect must be managed. Fourth, because each dose contains amounts of medication that are greater than deemed prudent or advised if administered as an immediate-release treatment, it is important not to manipulate the tablet, capsule, or patch by biting, crushing, chewing, dissolving, or taking the medication with alcohol as it will significantly alter the pharmacokinetics and will increase the chance of serious adverse effects. Finally, patients must be counseled as to the importance of properly disposing unused medications, so that residual drug is not inadvertently consumed by an unintended recipient, eg, human and nonhuman scavengers.

\section{Potential limitations to improvements for patients and prescribers}

In the ideal setting, the introduction of new extended-release formulations of hydrocodone should afford the potential to help a larger number of those in need. Unfortunately, we do not practice in a perfect world. Fears held by patients, 
physicians, and society about the real and the imagined consequences associated with the use of opioid medications already limit their use in managing pain for a large number of individuals with valid pain complaints. ${ }^{3,4,10,37-40}$ It is disappointing that the most effective medications used in our striving to provide comfort while doing no harm are frequently misused, abused, and diverted leading to harm in appropriately treated patients, unintended recipients, and society as a whole. The release of the new hydrocodone formulations has fueled the controversy surrounding whether long-term treatment with opioid medications provides pain relief that is sufficient enough to offset the risks of the significant negative aspects that develop with increased frequency and severity during long-term treatment and the unprecedented and regretful consequences that have resulted from the recent overprescribing of controlled analgesics.

A frequently reported truth is that there is "no substantial evidence for the maintenance of pain relief or improved function over long periods of time without incurring serious risk of overdose, dependence, or addiction". ${ }^{8}$ When taken in the context of the literature that clearly demonstrates the rapid increase in the prescribing of opioid medications that has taken place in the last 30 years parallels an unprecedented and correspondingly steep increase in opioid-associated morbidity and mortality and the frequent, subjective impression that many patients who receive regular treatment with opioid medications seem to show little change in their reported pain scores and levels of activity, raises strong concern over the prudence of using opioid medications for the treatment of chronic pain in general. Within the context of significant unmet need, the current constraints on providing pain care in clinical practice and the relative lack of education and experience for providers that are responsible for providing care and the majority of prescriptions, ${ }^{4,7,8,37}$ the concerns raised by these reports seem to be valid and applicable for the population as a whole.

When considering a response to these concerns, it is important to remember that as much as the lack of evidencebased research fails to support the long-term use of opioid medications for treating chronic pain of nonmalignant origin, it also fails to provide evidence for withholding or withdrawing opioid treatment from those for which benefit can be demonstrated. ${ }^{8}$ The evidence that shows a direct relationship between the increase in opioid-related deaths and the increase in prescriptions written for opioid medications is clear and irrefutable. Most of the deaths, however, are related to errors in taking the medication and to the fact that many of the medications are taken by individuals who are not under the care of a physician or a pain specialist and for whom there is no medical need. ${ }^{3,4}$ There is little, if any, evidence reported on what portion of the pain population that is treated appropriately by trained specialists has realized significant improvement in pain control and quality of life as a result of the increased prescribing.

A paucity of good evidence does not necessarily mean that good evidence is not attainable. ${ }^{4}$ Well-designed, blinded, and controlled, long-term studies can take years to perform and are very expensive. Support for such massive studies is not readily available, especially if the prevailing opinion is that the outcome is already known, and there are ethical issues in controlled trials related to withholding potentially beneficial treatments from patients with moderate-to-severe pain for periods of years. Current databases generally have not been designed or have not been queried to determine whether any beneficial effects could be identified as a result of the increase in the prescribing of opioid medications. If so, which populations might have shown improved survival, decrease in comorbid health issues, or a reduction in the utilization of the health care system, adverse effects, function, and quality of life? Might certain groups in the general population show a decrease in pain-related suicide attempts or completions or the frequency of misuse, abuse, and diversion when compared with a similar demographic population that received treatment with and without opioid medications under the care of physicians with training in pain management who might have been helped as a result of receiving opioid medications?

The recent reports that have shown that there has been a reduction in the number of opioid-related deaths in response to the downward trend for prescribing opioid medications are encouraging, ${ }^{38}$ but they fail to address to what degree the decreased availability of opioid medications may also have affected the number of deaths by suicide associated with uncontrolled pain or the number of legitimate pain sufferers that report significant reduction in mood, ability to function independently, level of activity, quality of sleep, and overall quality of life. When weighing the outcomes and conclusions drawn from studies that analyze selected demographic data, it is important to understand that the selection of queries may be designed to reveal a desired result that is driven not by a well-constructed and testable hypothesis but by a predetermined conclusion. In the absence of a viable alternative to opioid analgesics to improve safety and reduce unnecessary suffering, caution should be exercised not to inflate the significance of the available data based on the urgency of the presentations to justify the blanket implementation of policy that in the hope of achieving a quick stoppage or reversal of 
the untoward outcomes inadvertently, further limits care for a large minority of patients with legitimate needs who may or already do respond to long-term opioid care. ${ }^{4}$

For patients who already perceive opioid medications as evil and have strong concerns about their potential deleterious effects, the controversy and sensational coverage of the ill-advised approval of extended-release hydrocodone and the resulting enhancement of public scrutiny ${ }^{39,40}$ may add to patients' reluctance to take opioid medications. The fear of being looked upon as being a drug addict even though there are legitimate reasons for taking opioid medications, contributes to the under-treatment of pain. The stigma of being viewed as an addict is frequently perceived by patients as synonymous with being a "bad person" and may for them preclude the consideration of using opioids under any condition despite a poor quality of life for the many who would benefit from their use. ${ }^{41}$

For physicians who have had minimal training in assessing pain, the use of opioid medications and the tools for monitoring responses to long-term care; the lack of evidencebased support for selecting opioid medications in the clinical regimen; ${ }^{4,8}$ and the increasing disparity between the time required to properly evaluate, diagnose, assess risk, and monitor for effective treatment and compliance and the rate of compensation for these activities are strong deterrents to consider the use of opioid medications in their spectrum of options. For some physicians, this leads to the decrease or elimination of the use of opioid medications in their practice. ${ }^{42}$ When the cost associated with providing reasonable, safe and appropriate pain care is coupled with limited education and little clear guidance for appropriate prescribing, there is little incentive for physicians who wish to attempt to help to do so. These issues effectively contribute to a reduction in the number of practitioners who are willing to provide comprehensive care for those in need, further reducing the resources for available care and the potential for realizing significant benefits from the approval of extended-release hydrocodone.

Regrettably, many of the resources being directed toward rapid amelioration of the obvious consequences of opioid use such as placing limits on the dose of opioid medication that is allowed for the management of chronic pain ${ }^{8,43}$ do little to correct the underlying problem, ie, poorly managed and undertreated pain, but inadvertently may take the decision-making out of the hands of experts and serve to inappropriately and unduly limit the access to medications needed by many. When the use of important tools is denied to acknowledged experts in a given field, the potential for achieving beneficial solutions to a given problem is severely reduced, if not eliminated, yet the expectation for success often remains unchanged.
The rationale behind implementing limitations on the amount of medications that are considered to be prudent is that if fewer medications are prescribed, there will be less medication that will be diverted to those who should not be using them, but it is unclear whether the limitation of drug supply alone is sufficient to reduce or correct the problem of drug abuse and its associated consequences or whether the limitation of supply redirects the problem to an equally damaging practice, eg, reduction in opioid prescriptions and pain coverage leading to increase the utilization of heroin. ${ }^{4446}$

Despite the "clear and present danger" medications, it is important that we do not let fear cloud reason and distort our realization of the fact that although the use of opioid medications is not free of pitfalls, for many patients with chronic moderate-to-severe pain, opioid medications are the only available option. As with any prescription medication, if used properly, for the right reasons, taking reasonable precautions to limit adverse effects such as opting for formulations that incorporate an abuse deterrent, and profiting from acquired knowledge, wisdom, and good judgment, we can care for our patients and achieve a desirable effect and may be able to realize the anticipated benefits made possible by the introduction of the extended-release formulations of hydrocodone.

\section{Disclosure}

The authors report no conflicts of interest in this work.

\section{References}

1. Gould HJ 3rd, Paul D. Hydrocodone extended-release: pharmacodynamics, pharmacokinetics and behavioral pharmacology of a controversy. Pharmacol Res. 2014;91:99-103.

2. Jones CM, Paulozzi LJ, Mack KA. Alcohol involvement in opioid pain reliever and benzodiazepine drug abuse-related emergency department visits and drug-related deaths - United States, 2010. MMWR Morb Mortal Wkly Rep. 2014;63:881-885.

3. Miller M, Barber CW, Leatherman S, et al. Prescription opioid duration of action and the risk of unintentional overdose among patients receiving opioid therapy. JAMA Intern Med. 2015;175(4):608-615.

4. Reuben DB, Alvanzo AA, Ashikaga T, et al. National Institutes of Health Pathways to Prevention Workshop: the role of opioids in the treatment of chronic pain. Ann Intern Med. 2015;162(4):295-300.

5. Leonard J, Paulozzi LJ, Jones CM, Mack KA, Rose A, Rudd RA. Vital signs: overdoses of prescription opioid pain relievers: United States, 1999-2008. MMWR Morb Mortal Wkly Rep. 2011;60(43):1487-1492.

6. Jones CM, Mack KA, Paulozzi LJ. Pharmaceutical overdose deaths, United States, 2010. JAMA. 2013;309(7):657-659.

7. Volkow ND, Frieden TR, Hyde PS, Cha SS. Medication-assisted therapies - tackling the opioid-overdose epidemic. N Engl J Med. 2014; 370(22):2063-2066.

8. Franklin GM. Opioids for chronic noncancer pain: a position paper of the American Academy of Neurology. Neurology. 2014;83(14): 1277-1284.

9. American Academy of Pain Medicine [database on the Internet]. Facts and Figures on Pain: Incidence of Pain as Compared to Major Conditions. Available from: http://www.painmed.org/patientcenter/ facts_on_pain.aspx\#incidence. Accessed July 21, 2015. 
10. Institute of Medicine of the National Academies. Relieving Pain in America: A Blueprint for Transforming Prevention, Care, Education, and Research. Washington, DC: The National Academies Press; 2011.

11. Mäntyselkä P, Kumpusalo E, Ahonen R, et al. Pain as a reason to visit the doctor: a study in Finnish primary health care. Pain. 2001; 89(2-3):175-180.

12. Hajj A, Khabbaz L, Laplanche J-L, Peoc'h K. Pharmacogenetics of opiates in clinical practice: the visible tip of the iceberg. Pharmacogenomics. 2013;14(5):575-585.

13. Sweeney BP. Pharmacogenomics and anaesthesia: explaining the variability in response to opiates. Eur J Anesthesiol. 2007;24(3):209-212.

14. Xie H-G, Frueh FW. Pharmacogenomics steps toward personalized medicine. Pers Med. 2005;2(4):325-337.

15. Paul D, Pasternak GW. Opioids and the control of pain. In: Pullan L, Patel J, editors. Neurotherapeutics: Emerging Strategies. Totowa, NJ: Humana Press Inc.; 1996:167-192.

16. Chou R, Fanciullo GJ, Fine PG, et al. Clinical guidelines for the use of chronic opioid therapy in chronic noncancer pain. J Pain. 2009; 10(2):113-130.

17. Reder RF. Opioid formulations: tailoring to the needs in chronic pain. Eur J Pain. 2001;5(Suppl A):109-111.

18. Coleman FS, Kay J. Biology of addiction. Obstet Gynecol Clin North Am. 1998;25(1):1-19.

19. Crowley TJ. The reinforcers for drug abuse: why people take drugs. Compr Psychiatry. 1972;13(1):51-62.

20. Larson AM, Polson J, Fontana RL, et al. Acetaminophen-induced acute liver failure: results of a United States multi-center, prospective study. Hepatology. 2005;42(6):1364-1372.

21. Llamas M [database on the Internet]. FDA Sets Acetaminophen Dose Limit, Warns of Liver Damage; 2014; Available from: http://www. drugwatch.com/2014/01/28/fda-limits-acetaminophen-liver-damage/. Accessed March 24, 2014.

22. Fordyce WE. Learning factors in pain. Scand J Rheumatol Suppl. 1989;82:13-17.

23. Fordyce WE, Fowler RS Jr, Lehmann JF, Delateur BJ, Sand PL, Trieschmann RB. Operant conditioning in the treatment of chronic pain. Arch Phys Med Rehabil. 1973;54(9):399-408.

24. Linton SJ, Melin L, Götestam KG. Behavioral analysis of chronic pain and its management. Prog Behav Modif. 1984;18:1-42.

25. Treisman GJ, Clark MR. A behaviorist perspective. Adv Psychosom Med. 2011;30:8-21.

26. American Pain Society. Principles of Analgesic Use in the Treatment of Acute Pain and Cancer Pain. 4th ed. Chicago, IL: American Pain Society; 1999:1-64.

27. Nicholson B. Benefits of extended-release opioid analgesic formulations in the treatment of chronic pain. Pain Pract. 2009;9(1):71-81.

28. Zimmermann M, Richarz U. End-of-dose pain in chronic pain: does it vary with the use of different long-acting opioids? Pain Pract. 2013; 14(8):757-769.

29. Hudcova J, McNicol E, Quah C, Lau J, Carr DB. Patient controlled opioid analgesia versus conventional opioid analgesia for postoperative pain. Cochrane Database Syst Rev. 2006;4:CD003348.

30. Kluger MT, Owen H. Patient-controlled analgesia: can it be made safer? Anaesth Intensive Care. 1991;19(3):412-420.
31. Viscusi ER. Patient-controlled drug delivery for acute postoperative pain management: a review of current and emerging technologies. Reg Anesth Pain Med. 2008;33(2):146-158.

32. Argoff CE. Recent management advances in acute postoperative pain. Pain Pract. 2014;14(5):477-487.

33. Flugsrud-Breckenridge MR, Gervitz C, Paul D, Gould HJ 3rd. Medications of abuse in pain management. Curr Opin Anaesthesiol. 2007; 20(4):319-324.

34. Fordyce WE. Learned pain: pain as behavior. In: Loeser JD, Butler SH, Chapman CR, Turk DC, editors. Bonica's Management of Pain, 3rd ed. Philadelphia, PA: Lippincott Williams \& Williams; 2001:478-482.

35. Fine PG, Portenoy RK. Establishing "best practices" for opioid rotation: conclusions of an expert panel. J Pain Symptom Manage. 2009; 38(3):418-425.

36. Manchikanti L, Abdi S, Atluri S, et al. American Society of Interventional Pain Physicians (ASIPP) guidelines for responsible opioid prescribing in chronic non-cancer pain: part I - evidence assessment. Pain Phys. 2012;15(Suppl 3):S1-S65.

37. Webster LR. Pills, polices, and predicaments: the unintended consequences of a health care system's policy toward opioids. Pain Med. 2013;14(10):1439-1440.

38. Dart RC, Surratt HL, Cicero TJ, et al. Trends in opioid analgesic abuse and mortality in the United States. N Engl J Med. 2015;372(3): 241-248.

39. Vallerand A, Nowak L. Chronic opioid therapy for nonmalignant pain: the patient's perspective. Part II - Barriers to chronic opioid therapy. Pain Manag Nurs. 2010;11(2):126-131.

40. Zuccaro SM, Vellucci R, Sarzi-Puttini P, Cherubino P, Labianca R, Fornasari D. Barriers to pain management: focus on opioid therapy. Clin Drug Investig. 2012;32(Suppl 1):11-19.

41. Baratta JL, Schwenk ES, Viscusi ER. Clinical consequences of inadequate pain relief: barriers to optimal pain management. Plast Reconstr Surg. 2014;134(4 Suppl 2):15S-21S.

42. Atkinson TJ, Schatman ME, Fudin J. Recent advances in the pharmacological management of acute and chronic pain. J Pain Res. 2014; 7:265-268.

43. Washington State's guideline on use of opioids for chronic non-cancer pain - frequently asked questions. Olympia, WA: Agency Medical Director Groups; 2010; Available from: www.agencymeddirectors. wa.gov/Files/2006FAQV8.pdf. Accessed July 28, 2015.

44. Volkow ND. Prescription Opioid and Heroin Abuse. National Institute on Drug Abuse. The Science of Drug Abuse and Addiction. Bethesda, MD: National Institutes of Health; 2014.

45. Rudd RA, Paulozzi LJ, Bauer MJ, et al. Increases in heroin overdose deaths - 28 states, 2010 to 2012. MMWR Morb Mortal Wkly Rep. 2014; 63(39):849-854.

46. Bernstein L. Heroin deaths have quadrupled in the last decade. The Washington Post; 2015 July 7. Available from: http://www. washingtonpost.com/news/to-your-health/wp/2015/07/07/heroindeaths-have-quadrupled-in-the-past-decade/. Accessed July 28, 2015.

47. Clancy T. Clear and Present Danger. New York, NY: Berkley Books: The Berkley Publishing Group a division of Penguin Group (USA) Inc.; 1989.
Therapeutics and Clinical Risk Management

\section{Publish your work in this journal}

Therapeutics and Clinical Risk Management is an international, peerreviewed journal of clinical therapeutics and risk management, focusing on concise rapid reporting of clinical studies in all therapeutic areas, outcomes, safety, and programs for the effective, safe, and sustained use of medicines. This journal is indexed on PubMed Central, CAS,

\section{Dovepress}

EMBase, Scopus and the Elsevier Bibliographic databases. The manuscript management system is completely online and includes a very quick and fair peer-review system, which is all easy to use. Visit http://www.dovepress.com/testimonials.php to read real quotes from published authors. 